\title{
Arte y Costumbres: Los pliegues azules en los vestidos de vinilo de Laura Lima (1990-2010)
}

\section{Montedônio Chagastelles, Gianne Maria}

Resumen:

El artículo trata de la instancia

"Costumes" creada por la artista brasileña contemporánea Laura Lima, entre los años 1990 y 2010. En esta obra, Lima propone un cambio de hábitos y ofrece nuevas costumbres y nuevos vestidos para que el espectador incorpore en su día a día. El deseo de vestir las "Costumbres" propuestas lleva al espectador a cambiarse. Este hecho posibilita que el espectador viva la desterritorialización de su identidad, permitiéndose vivir una subjetividad abierta al porvenir. Lo esencial en estas obras, además de la estetización de objetos y espacios, es también la confrontación de los participantes con situaciones artísticas. El interés se

\section{Cuadernos del Centro de Estudios de Diseño y Comunicación N76}

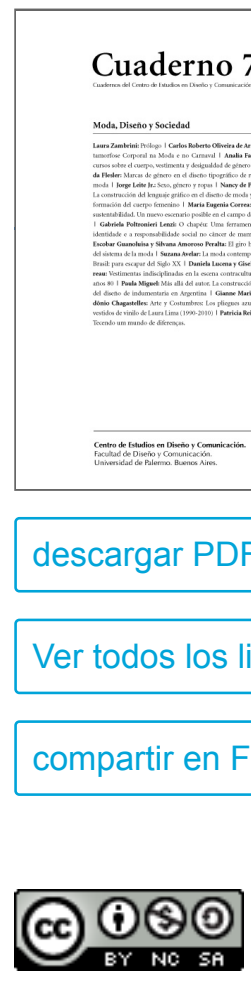

Esta obra está bajo una Licencia Creative Commons Atribución-NoComercialCompartirlgual 4.0 Internacional concentra en los comportamientos: ampliación de la percepción, actualización de las memorias, cambios de costumbres y renovación de la sensibilidad. Se discute el ambiente del arte y de existencia del hombre en su cotidiano y las formas de control del espacio y del cuerpo del sujeto, así como las estrategias de resistencia a través de la búsqueda del anonimato y de formas singulares de apropiación de nuevas costumbres.

Palabras clave: Vestidos - Costumbres - Pliegues - Arte contemporáneo - Laura Lima - Memoria - Resistencia

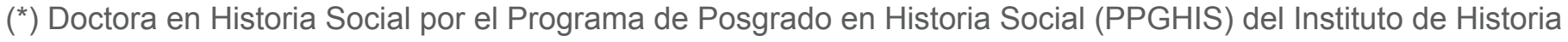
(IH) de la Universidad Federal de Rio de Janeiro (UFRJ). Profesora Adjunta y coordinadora de Historia del Arte y Artes Visuales de la Universidad del Estado de Rio de Janeiro (UERJ). Autora de las siguientes obras: Alegoria na arte brasileira (1980-2000). Rio de Janeiro: Multifoco, 2013; y Eternidade do efêmero: memória e vivência na arte brasileira dos anos 90 - Jarbas Lopes, Laura Lima e Cabelo. Rio de Janeiro: Multifoco, 2012. Organizadora del libro Ensaios de imagens: cidades. Rio de Janeiro: Multifoco, 2016. 
Como forma de intervención astuta, política y artística, Laura Lima desarrolla una instancia llamada Costumes1 . La artista prefiere llamar instancias, en lugar de series, la división de sus trabajos, pues, según Laura, serie acuerda secuenciación, algo hecho en gran escala y con un mismo patrón (recordando algo industrializado), mientras instancia remite a instancias de pensamiento, a un conjunto de actos de un proceso. Cada instancia es constituida por un conjunto de ideas que poseen semejanza entre las imágenes. La instancia Costumes se trata de un conjunto de ropas-esculturas hechas en vinilo que deben de ser manoseadas y vestidas por los espectadores. En este contexto, Costumes es una ornamentación de cuerpo hecha siempre con el mismo material: vinilo azul claro. Este material permite una infinidad de posibilidades, de pliegues. Pero siempre es el vinilo -cortado, retirado, plegado, tranzado- y el pegamento. De esta manera, la materialidad del trabajo (el pliegue de un mismo elemento) remite a una obra que incorpora lo móvil y múltiple que, en su propia fabricación, como construcción entrenzada es esquiva a cualquier solidificación. En el vocabulario del vestuario, tan próximo a todos nosotros, encontramos prendas en Costumes de difícil nombramiento: prendas de cabeza, de mano, de brazo, de hombro (muchas veces difíciles de nombrar y reconocer). Sin embargo, su toque suave y frío también tiene algo de erótico y prohibido. Debemos recordar que el vinilo es un material muy utilizado en la indumentaria erótica y fetichista. En la moda pornográfica, la materialidad fetichista del vinilo evoca imágenes de "sexo raro" en el que llama la atención prendas de vestir tales como: botas, corsés, objetos fálicos. Existen elementos sensuales que valoran el cuerpo y la apariencia, como los objetos de vinilo, y por eso, la importancia extrema del hedonismo, de un desarrollo festivo del cuerpo que solamente hace sentido por la presencia del otro. Sin embargo, según Steele (1997), la indumentaria erótica tiene como color principal el negro, por estar asociado al misterio y al poder. No obstante, Laura Lima crea un contraste utilizando el vinilo en el color azul bebé. El cuerpo es construido para ser visto y es teatralizado a su máximo en las publicidades, la moda y lo cotidiano. Éste es ornado para ser exhibido como espectáculo. Es decir, se enfatiza la sensación colectiva. El culto al cuerpo y la imagen se vuelve colectivo, pues no es un fenómeno individual o narcisista sino un fenómeno global (Maffesoli, 2005). El cuerpo, entonces, se vuelve múltiple y móvil, tal como se manifiesta en los vestidos de Laura Lima de su obra Costumes (Ver Figuras 1 y 2).

Las Costumbres2 son presentadas en una habitación de un museo o una galería -llamadas de tiendas o boutiques-, allí los espectadores pueden probarlas en el ritual simple y cotidiano de escoger una ropa. Pueden usar, modificar, alterar y hasta comprar su propia Costumbre. Y si bien, no todos pueden comprar, al menos todos pueden probarlas en el museo. Además, el espectador tiene la posibilidad de crear su propia Costumbre en un taller abierto para este fin. Así, el espectador puede ser creador y participante de la propia obra. Las Costumbres son exhibidas en una instalación creada con maniquíes, espejos y asientos, en un contexto que remite a una tienda de ropas y al fetiche. Intitulada "Costumes Loja"3, esas habitaciones contienen evidente carga crítica al transformar una galería de arte y/o un museo en una tienda de ropas. En ese sentido, una galería es un lugar de ventas de mercaderías y de arte; lo que Laura Lima hace es incorporar al lugar es el trabajo. Las prendas funcionan como metáfora, no sólo del funcionamiento mercantilista de la sociedad, sino también de las estructuras y comportamientos viciados presentes en el mundo del arte. Es decir, la relación entre espectador y obra, así como las formas esperadas de acción de cada uno en dicho sistema.

Este trabajo es vinculado a una problemática antropológica, característica sobresaliente en la obra de Laura Lima: en este caso, la vestimenta como modo de identificación. La palabra Costumes puede remitir a un hábito tener costumbre de- o a vestimentas e indumentarias (Ver Figuras 3 y 4 ) 
Sin embargo, la propuesta sólo es completada cuando, después de la exposición, Laura invita a los espectadores participantes a vivir la experiencia en un lugar allá del museo, como por ejemplo, la ida de los espectadores vestidos de Costumbres a una discoteca y/o a tomar un té. Lo importante es estimular la incorporación de las nuevas Costumbres a sus actos cotidianos. Laura investiga un lugar en el que el público tenga el hábito de frecuentar después de la exposición y les propone la vivencia. Así, la Costumbre como indumentaria modifica las situaciones vividas. Por ejemplo, al tomar un té o al salir a una discoteca. La invitación de la artista para que el participante se vista con las Costumbres, viva fantasías y sensaciones inmediatas en el contacto físico de su cuerpo con el material es distinta según los diferentes públicos, dependiendo en gran medida de la cultura de ellos. Por ejemplo, el público que experimentó esta proposición en Eslovenia en 2002, presentó comportamientos y participaciones diferentes del público que vivió esta actividad en el Museo de Arte de Pampulha, en Belo Horizonte en 2002, o en la Galería Casa Triângulo, en São Paulo en 2003. (Ver Figuras 5 , 6 y 7 )

La participación va en búsqueda de sensaciones adormecidas y básicamente, sin el espectador la obra no ocurre. En ese sentido, sólo se puede comprender la experiencia vistiendo las Costumbres. Al mismo tiempo, el espectador también es parte de la obra porque, si no estuviera dentro del vestido nada acontecería. Así, en Costumbres la ropa queda bajo la dependencia del participante, esperando que éste le atribuya un significado. Por lo tanto, Laura estimula en el participante un proceso de des-condicionamiento y, es solo a través de ese proceso, que el participante puede intentar liberarse de hábitos ya adquiridos. Para la artista, esos ornamentos están en la galería (o en el museo) para ir a la vida misma. La participación que Laura propone exige un proceso de apertura, tanto del participante como de la proposición, y reclama igualmente una toma de conciencia de la propuesta y de sus reglas. Es decir, el conocimiento de las reglas y su aceptación - que no es pasiva - se encuentran en las condiciones del juego y de la diversión posible entre participantes, es decir, la posibilidad de la obra. En el interior de ese juego, se opera el carácter de una apertura que ocasiona el comportamiento creativo. (Ver Figura 8)

En ese sentido, Laura dirige sus investigaciones hacia las relaciones entre su obra y la participación sensorial del espectador, a través de una serie de propuestas que ponen en acto las emociones que se experimentan al vestir las Costumbres. El espectador se divierte con el mundo que lo rodea, por lo tanto, su obra nos hace percibir otra característica importante: lo lúdico. ¿Por qué? Pues, en el juego el sujeto crea una situación imaginaria, buscando satisfacer sus necesidades inmediatas, o sea, la actividad lúdica es motivo para la acción. Según Vygotsky (1998), las experiencias de situaciones lúdicas contribuyen con un proceso de aprendizaje más significativo, pues, a través del juego, el sujeto se entrega sin armas a la actividad. Debemos recordar también el placer que esas actividades proporcionan al jugador, aunque se enfrenten obstáculos, a través de ellas se satisface la necesidad de una acción. Todavía, no menos significativa es la insistencia de Laura en el gozo que el juego propicia al espectador. Las actividades lúdicas presuponen una dinámica propia y diferente a las demás, ya que en ella está presente el imaginario social. Así, la experiencia lúdica que la obra de Laura proporciona, recrea condiciones para el establecimiento de relaciones entre los conocimientos nuevos y los anteriores, favoreciendo la comprensión de nuevas ideas. Por lo tanto, se puede decir que otra de las ventajas en esta obra lúdica, está en el descubrimiento y la posibilidad que tiene el ser humano de crear y re-crear. En suma, el participante se vuelve el motor y núcleo de la obra. Es en esa experiencia particular que el participante actualiza sus memorias y vive otras que serán actualizadas en su vida activa. Por lo tanto, la obra es la creación del propio acto y de la continuidad en la duración. En esa experiencia artística la imagen surge y desaparece, 
afectando al espectador-participante que, debido a esa rápida percepción, eterniza en la memoria el encuentro fugaz y la posibilidad de un despliegue de ese acontecimiento: la eternidad de lo efímero (Chagastelles, 2012).

Uno de los aspectos más subversivos de la obra de Laura es que, a partir del momento en que el arte empieza a trabajar cualquier materia del mundo y a interferir directamente en él, se explicita de manera más contundente que el arte en la contemporaneidad se caracteriza por ser una "prática de problematização: decifração de signos, produção de sentido, criação de mundos"4 (Rolnik, 2002, p. 270).

Es exactamente en esta actuación en la vida contemporánea que la práctica estética de Laura Lima hace obra, volviendo la forma indisociable de su efecto de problematización del mundo. El trabajo de Laura Lima participa del desciframiento de signos de las mutaciones sensibles, inventando formas a través de las cuales tales signos ganan visibilidad y se integran al mapa vigente. Desde esta óptica, el arte sería, por lo tanto, una práctica de experimentación que participa del cambio del mundo. En esa línea, Rolnik (2002) resalta que el arte no se reduce al objeto que resulta de su práctica, pero que él es esa práctica como un todo: práctica estética que abraza la vida como potencia de creación en los diferentes medios en los que opera. "Seus produtos são apenas uma dimensão da obra e não "a" obra: um condensado de signos decifrados que introduz uma diferença na realidade"5 (Rolnik, 2002, p. 270).

En este sentido, Costumes es una obra vivencial en la que existe la recreación del arte como vida a partir de una poética ritualista del gesto del espectador. Así, lo que vale es lo que él ha experimentado. Son obras vivenciales, con fuerza de contagio y atmósferas de creación e invención. A través de la acción el espectador vive la obra como una experiencia abierta e indeterminada en la que las fuerzas del deseo se afirman en su duración. La apertura de las proposiciones adquieren su máxima intensidad, pues remiten a vivencias no condicionadas. Luego, estas proposiciones articulan acciones y comportamientos, creando una atmósfera de invención en que no todo está previamente determinado. La instancia Costumes cambia la concepción de artista: no es más un creador de objetos para la contemplación sino que Laura se vuelve una productora colectiva para la creación. Es decir, el arte como una intervención cultural. Su campo de acción no es el sistema de arte, sino la actividad colectiva que estimula la subjetividad estética hipoatrofiada de los espectadores en nuestra sociedad. Esas obras son entendidas como producciones para la creación pues tienen como principio la participación, lo lúdico y la invención del espectador. La obra solo se completa con esa interacción. El espectador tiene la posibilidad de experimentar la creación, de descubrir y reinventar. Lo que está en juego es su poder de agenciar relaciones, su impulso vital tal como afirmara Bergson (1999).

Toda la unidad estructural de esta obra está basada en la acción del espectador, quien mientras se viste con la Costumbre, revela el sentido expresivo de la obra. La idea de la ropa ya consolida más ese punto de vista: el espectador viste la Costumbre, que se constituye con vinilo azul y se revela, a medida que el espectador se mueve, anda, danza, toma el té y, en tantas otras actividades de la vida cotidiana. La obra requiere ahí la participación corporal directa; además de revestir el cuerpo, hace con que el individuo incorpore nuevos hábitos. El propio acto de vestir la obra implica una transmutación expresivo-corporal del espectador. Así, la obra no es estática y ni es ubicada en un lugar fijo sino que es una vivencia con múltiples posibilidades. Luego, Laura busca la incorporación mágica de los elementos de la obra como tal, en una vivencia del espectador.

El vestir, sentido más amplio de Costumes, se contrapone al contemplar. El uso de la ropa en el arte de Laura Lima tiene como referencia histórica en Brasil a las obras los Parangolés (1964-67) de Hélio Oiticica y las 
Máscaras (1967) de Lygia Clark. La creación de los Parangolés, según Nelson Aguilar (1994) causó un impacto muy fuerte en la época que mismo Lygia Clark, gran compañera de camino de Oiticica, comentó: "O que está acontecendo? Isso é coisa de costureiro e não de artista"6 (en Aguilar, 1994, p. 3). Luego, sin embargo, ella percibió lo que sucedía y comenzó a utilizar la lección de la más joven, cuando realizó sus Máscaras sensoriais. Así, el uso de la ropa en el arte incide directamente sobre la obra de Laura Lima. Por su parte, Lisette Lagnado (2001) reafirmó esta influencia de la ropa en el arte de Laura, en las siguientes palabras: "Os Parangolés de Oiticica, A casa é o corpo e as Máscaras de Clark têm ricos desdobramentos nos trabalhos de Laura Lima" (Lagnado, 2001, p. 374)7 .

Tal como se dijera, este trabajo considera que el arte vivencial de Laura Lima posee referencias en la historia del arte brasileño, principalmente, en torno a la discusión acerca del artista como productor colectivo, en especial en las obras de Hélio Oiticica y Lygia Clark de las décadas de 1960 y 1970. Estos artistas lograron superar los límites del formalismo y lo hicieron por vía de una apertura al espacio tridimensional, enfrentando, de esta manera, todos los problemas de orden plástico, antropológico y/o político que ese pasaje al espacio les imponía. En las décadas de 1960 y 1970, el arte brasileño vivió una crisis en relación a su propia muerte, renunciando al objeto de arte y declarando una ruptura con el sistema del arte en sentido amplio. Los materiales utilizados eran precarios y muchas veces efímeros, anunciando la posibilidad del arte de liberarse de sus aspectos objetuales, cosificados y mercadológicos y en pos de ejercer un proyecto socio-político. Los artistas crearon estrategias simbólicas y metafóricas para liberarse de la dictadura militar, apuntando a la necesidad de interacción con el público/espectador y problematizando el vacío del sistema de las artes.

Entre los años de 1990 y 2000, Laura Lima comenzó a realizar la instancia Costumes, generando una relación de intensidad temporal con los años 1960 y 1970 en lo que se refiere al arte como experiencia, en la que el artista, además de su tradicional papel de sujeto creador, que mantiene su pertenencia, también pasó a pensarse como un productor colectivo. Una de las características más marcantes de esa generación de los años 1990 y 2000 fue la multiplicidad de lenguajes: performance, arte del cuerpo, instalación, instauración, video, poesía, fotografía, acción, pintura. Es decir, resurgieron las discusiones acerca del arte efímero, del material precario y el uso de soportes no convencionales tales como espacios naturales y urbanos y/o el uso del cuerpo en una obra. Sin embargo, a diferencia de los años 1960 y 1970, cuando se desarrollaba un proyecto sociopolítico específico en el que el cuerpo en el arte aparecía como vía de rechazo y rebeldía de un status quo moralista y represor; a excepción de Lygia Clark, el cuerpo en el arte de las décadas de 1990 y 2000 fue asociado a la invención subjetiva, a una poiesis del sujeto que está cambiando cotidianamente. El arte de los años 1990 y 2000 ha estado interesado en suscitar cuestiones acerca del destino del sujeto, buscando el sentido de su existencia en el mundo de hoy y trayendo a la vez, la crisis del sujeto en el mundo contemporáneo. En ese sentido, esos artistas se preocupan enfáticamente del ser en comunidad. Luego, el arte contemporáneo brasileño se ha posicionado especialmente contra la máquina de la globalización neoliberal y el canibalismo de la producción artística en el sistema comercial.

Desde el arte vivencial, surge una expresión de una mirada que ya no se contiene solamente en la contemplación del objeto bidimensional, mirada ésta que se traduce en percepción producto de su época. Por ejemplo, Benjamin nos habló de una percepción de choque (Benjamin, 1982, p. 235). Según el autor, es necesario que el arte contenga un poder traumático. Solamente así se logra mobilizar el espectador, incluyéndolo de forma activa y sensorial en la obra. Este nuevo tipo de percepción, por su capacidad de estimular acciones, está más próxima de expresar la sensibilidad de su tiempo. 
Con todo, en los años 1990 y 2000, el sistema de corporaciones reestructuró rápidamente las relaciones construidas sobre un terreno globalizado. La caída del muro de Berlín y el final del comunismo reajustaron las estructuras políticas mundiales en favor del neoliberalismo, que también hoy ha empezado a colapsar con la creciente monopolización de los medios tecnológicos e informativos. El HIV, la Ébola y otros virus fatales desafían un mundo que parecía dominado y controlado por la ciencia. La física cuántica, el proyecto genoma y las clonaciones de ADN relativizan conquistas científicas y presentan al mundo una estrecha y compleja ligación entre arte, ciencia y tecnología. El crecimiento de contaminantes, el desgaste de la capa de ozono, el calentamiento generalizado y gradual del planeta y la inminencia de la falta de agua generalizada a mediano plazo, hacen de la ecología un número creciente de grupos y ONGs, aunque exista la conciencia de que problemas ecológicos estén enmarañados en la red de intereses económicos dominados por el Primer Mundo. En ese escenario, la importancia dada a la moda, al mundo de las apariencias y actitudes, aliadas a una tecnología sofisticada de cirugías plásticas, implantes, aparatos de gimnasia, vitaminas y otras sustancias químicas, más allá de las posibilidades de modificaciones genéticas, hacen del cuerpo un campo de intervenciones. Internet y sus desdoblamientos virtuales construyen promesas de núcleos cibernéticos de vida (Canton, 2001).

En este contexto, los artistas de los años 1990 y 2000 asistieron al triunfo de la globalización, al aumento exponencial de la información mediática de masas, al desarrollo del mundo cibernético que fortalece la reproducibilidad virtual y el contacto humano a la distancia. El hombre de esta década vive aún más inestable y fragmentado. La resistencia a la creciente sensación de anonimato y amnesia en cada individuo, por lo impacto despersonalizante de la cultura de masas contemporánea, es una problemática que los artistas de esta época desarrollan en sus obras (Canton, 2001). Es decir, se forman planos de expresión cargado de valores antitéticos tales como eterno/efímero, real/virtual, vida/muerte, memoria/amnesia, local/global, identidad/anonimato; hoy, cada vez más evidentes en los dominios del arte. La durabilidad del objeto artístico es cada vez más corta, enfatizando el espíritu del tiempo de nuestros días en tanto pasajero e instantáneo. Así, el arte vivencial brasileño presenta determinadas características: la negación de la obra como objeto fijo y contemplativo, la movilización de la acción del participante, el uso del cuerpo como parte integrante de la obra, la revelación de la intuición en lo onírico y sensible, la problemática de la relación espacio-tiempo, la reacción a la muerte del arte. En ese sentido, la obra de Laura Lima coloca la potencia creativa del individuo como factor de construcción de lo real, dentro de un proyecto ambiental - proyecto entre hombre, vida, naturaleza y cultura- permeada por la experiencia del gesto creador y transformador. El arte de Laura Lima pretende elevar la estética a la esfera de la vida, entendiendo al arte como instancia de lo vivido, haciendo de él un principio ético de la existencia. Para ella, el museo es el mundo, la experiencia cotidiana y el arte son incorporaciones de lo sensible a lo lúdico. Estas intervenciones artísticas contemporáneas se relacionan con el uso plural de los cuerpos y los vestidos, así como también, con la posibilidad de huir de las expectativas de los dirigentes políticos, manteniendo la tensión entre la disciplina y la anti-disciplina.

Algunas consideraciones acerca de la relación entre la historia cultural y la historia del arte contemporáneo son fundamentales en la discusión sobre el reconocimiento de similitudes entre las maneras de usar el cuerpo y la moda, pero señalando las diferencias y singularidades propias de las personas en la contemporaneidad. El acto de recordar presupone múltiples posibilidades de elaboración de las representaciones y de reafirmación de las identidades construidas en la dinámica de la historia. Actualmente, una de las funciones sociales de la memoria histórica es justamente la resistencia al olvido, la búsqueda de identidades colectivas, la defensa de la 
preservación y del patrimonio cultural. En esa relación, entre la memoria y la historia, se puede pensar en, por lo menos, dos formas de intersección entre ambas. Una primera, en la cual la historia funciona como alimento de la memoria y simultáneamente la memoria puede ser tomada como una de las fuentes de información para la construcción del saber histórico. Y una segunda, en la que la historia asume una dimensión específica de cultura erudita y, en la búsqueda por la producción de evidencias, acaba por constituirse en un mecanismo destructor de la memoria espontánea. Para descifrar los usos plurales de las intervenciones artísticas contemporáneas se tornó relevante la utilización de ciertos análisis que buscan la interpretación cultural de la vida en sociedad. Algunos historiadores de la historia cultural proponen, de manera innovadora, a los espectadores en la condición de objeto y sujeto de la historia. Por ejemplo, los estudios de Roger Chartier (1990) que, caminando por los senderos abiertos por Michel de Certeau, plantean una idea de cultura como práctica y discute ese concepto utilizando categorías como representación y apropiación. Como propone Roger Chartier (1990), es la noción de apropiación, o sea, el reconocimiento de las invenciones creadoras en el proceso de recepción de los mensajes, la más correcta para pensar la cultura y la vida cotidiana de esos habitantes de la ciudad. Para Chartier (1990), "a aceitação das mensagens e dos modelos opera-se sempre através de ordenamentos, de desvios, de reempregos singulares"8 (1990, pp. 136-137). Entre el mundo de los espectadores del ambiente artístico de Laura Lima y de las prácticas cotidianas de la moda, las personas no reciben pasivamente el discurso del poder. La utilización de la teoría producida por Chartier prioriza las prácticas culturales, sin desconsiderar los procesos políticos, económicos y sociales que actúan junto a esas prácticas.

En ese sentido, una interpretación que huya de los modelos en los cuales los ciudadanos siempre aparecen manipulados y alienados se hace necesaria. Los conceptos de Michel de Certeau (1994), tales como "maneras de hacer" y "astucias cotidianas" permiten salir de esas esquematizaciones. Dichos conceptos, expuestos en la obra A Invenção do Cotidiano (1994), exploran la experiencia de apropiación del espacio urbano como un "lugar practicado". Por ejemplo, construir casas, producir utensilios, trabajar, cocinar, vestir ropas son hábitos heredados socialmente. Cualquier comunidad, antigua o moderna, puede ser definida por ese conjunto de tradiciones y usos. Laura Lima elude las costumbres en su proposición artística. Sus obras señalan la instauración de un ambiente que incluye la acción de los participantes como elementos constitutivos del acontecimiento estético. Las relaciones plásticas se vuelven vivencias de un espacio estetizado en pos de un territorio destinado a experiencias donde también los participantes se cambian a sí mismos. En las propuestas de Laura Lima, a través del arte como vivencia, se desarrolla la discusión sobre la memoria, la creación, la diferenciación y el arte como experiencia estética. Operan las posibilidades del desarrollo de la subjetividad estética hipo-atrofiada de los ciudadanos, y por lo tanto, la resistencia a la homogeneidad en el mundo globalizado se vuelve uno de los vectores principales que conducen su arte, así como las tácticas de resistencia a través de las formas singulares de apropiación de nuevos vestidos y costumbres. El control disciplinante busca ejercer un dominio sobre las personas, pero ellas huyen de éste a través de sus modos de usos y apropiaciones plurales de lo cotidiano. Conforme resaltara Michel de Certeau (1994), el poder disciplinador es burlado por medio de las apropiaciones astutas de los habitantes anónimos, haciendo que los modos de uso del espacio sean difíciles de ser regulados. Se percibe, un verdadero entusiasmo frente a lo nuevo e imprevisible; la invención y la libertad permean la obra de Laura Lima. En Costumes no existe nada inmóvil y fijo. Desde la perspectiva fundamentada por Bergson (1999), estamos inmersos en la duración, en un presente que dura; nuestra memoria no consiste en la regresión del presente al pasado sino al revés, en la proyección del pasado en el presente. Sin embargo, vivimos en un tiempo cada vez más fragmentado, instantáneo, efímero y poco experimentamos la temporalidad de la duración. Finalmente, la obra de Laura Lima busca rescatar el tiempo 
distendido de la duración, así como la valoración de la memoria del sujeto y el desarrollo de la subjetividad estética atrofiada en nuestra sociedad. Ello resulta fundamental como forma de resistencia a una sociedad pautada por una creciente amnesia y con dificultades de conceder la linealidad narrativa a lo vivido, de producir historia, trama, memoria y creación.

Notas

1. Costumes tiene como equivalente en español el vocablo "Costumbres", generalmente utilizado para referirse a la manera habitual de actuar o comportarse o la práctica tradicional de una colectividad o un lugar. Aunque se haya optado por mantener la palabra en portugués por el hecho de que se trata del nombre de la obra, su significación la puede buscar el lector que prefiera el referido correspondiente en español.

\section{Las ropas-esculturas.}

3. En español: "Costumbres Tienda".

4. "Práctica de problematicidad: descifre de signos, producción de sentido, creación de mundos".

5. "Sus productos son solamente una dimensión de la obra y no 'la' obra: un condensado de signos que introduce una diferencia en la realidad”. 6. “¿Qué está aconteciendo? Eso es cosa de costurero y no de artista”.

7. "Los Parangolés de Oiticica, A casa é o corpo y las Máscaras de Clark tienen ricos desdoblamientos en los trabajos de Laura Lima".

8. "La aceptación de los mensajes y los modelos se operan siempre a través de ordenamientos, de desvíos, de re-empleos singulares".

\section{Bibliografía}

Aguilar, N. (1994). Os Faróis Brasileiros. São Paulo: Catálogo das mostras organizadas a partir das salas especiais - Hélio Oiticica e Lygia Clark da XXII Bienal Internacional de São Paulo.

Benjamin, W. (1982). A obra de arte na época de sua reprodutibilidade técnica. 1936. In: Lima, Luiz Costa. (Organizador) Teoria da cultura de massa. Rio de Janeiro: Paz e Terra.

Bergson, H. (1999). Matéria e Memória: ensaio sobre a relação do corpo com o espírito. Tradução Paulo Neves. São Paulo: Martins Fontes.

Canton, K. (2001). Novíssima arte brasileira: um guia de tendências. São Paulo: lluminuras.

Certeau, M. de (1994). A invenção do Cotidiano. Petrópolis: Vozes.

Chagastelles, G. M. M. (2012). Eternidade do efêmero: memória e vivência na arte brasileira dos anos 90 Jarbas Lopes, Laura Lima e Cabelo. Rio de Janeiro: Multifoco.

Chartier, R. (1990). A História Cultural - entre práticas e representações. Lisboa: DIFEL. 
Clark, L. (1994). Como citado em: Aguilar, Nelson. Os Faróis Brasileiros. São Paulo: Catálogo das mostras organizadas a partir das salas especiais - Hélio Oiticica e Lygia Clark da XXII Bienal Internacional de São Paulo.

Lagnado, L. (2001). A instauração: um conceito entre instalação e performance. In: Basbaum, Ricardo. (Org.) Arte contemporânea brasileira: texturas, dicções, ficções, estratégias. Rio de Janeiro: Rios Ambiciosos.

Maffesoli, M. (2005). O mistério da conjunção: ensaios sobre comunicação, corpo e sociedade. Porto Alegre: Sulina.

Pedrosa, M. (1986). Mundo, homem, arte em crise. (Organização: Aracy Amaral). São Paulo: Perspectiva.

Rolnik, S. (2002). "Subjetividade em obra: Lygia Clark artista contemporânea". In: Gadelha, Sylvio \& Lins, Daniel (orgs). Nietzsche e Deleuze: que pode o corpo. Organizadores. Rio de Janeiro / Fortaleza: Relume Dumará e Secretaria da Cultura e do Desporto do Ceará.

Steele, V. (1997). Fetiche, Moda, Sexo e Poder. Rio de Janeiro: Rocco.

Vygotsky, L. S. (1988). A formação da mente. São Paulo: Martins Fontes.

Site

http://www1.folha.uol.com.br/fsp/acontece/ac1705200301.htm. Acesso: 22/08/2016

Abstract: This paper works on "Costumes", a piece created by a Brazilian contemporary artist called Laura Lima, between 1990 and 2010. On this work, Lima proposes a changing of habits while offering new ways of behave as well as offering new cloth, giving to the spectators the opportunity to embody it to daily life. The wish to dress up the "Costumes" proposed by her and the demand for different ways of administration make possible to the spectator to change himself. Hence, it becomes possible to the spectator to live the deterritorialisation of his own identity, allowing himself to experience an open subjectivity to the new comings. The essential of these pieces, beyond the aesthetisation of objects and spaces, is also the confrontation between participants and artistic situations. The interest is focused on the behaviours: enlargement of perception, updating of memories, changing of habits and renewal of sensibility. The artistic environment, the human existence, the way of control over the space and the human body are also of great importance to this present work, as well as the resistance strategies that go through the search for anonymity and particular appropriation of new behaviours.

Key words: Cloth - Habits - Folds - Contemporary Art - Laura Lima - Memory - Resistance.

Resumo: O artigo trata da instância "Costumes" criada pela artista brasileira contemporânea Laura Lima, entre os anos 1990 e 2010. Nessa obra Lima propõe uma mudança de hábitos, um descondicionamento de costumes e oferece novos costumes e novas vestes para que o fruidor incorpore ao seu dia-a-dia. O desejo de vestir os "Costumes", a busca de novos agenciamentos leva o fruidor a se transformar. Esse fato possibilita que o fruidor viva a desterritorialização de sua identidade, deixando-se viver uma subjetividade aberta para o devir. 0 essencial dessas obras, além da estetização de objetos e espaços, é também a confrontação de participantes com situações artísticas. $O$ interesse concentra-se nos comportamentos: ampliação da percepção, atualização das memórias, mudanças de costumes e renovação da sensibilidade. Discute-se o ambiente da arte e de 
existência do homem em seu cotidiano e as formas de controle do espaço e do corpo do sujeito, bem como as estratégias de resistência através da busca do anonimato e das formas singulares de apropriação de novos costumes.

Palavras chave: Vestes - Costumes - Dobras - Arte contemporânea - Laura Lima - Memó- ria - Resistência.

[Las traducciones de los abstracts fueron supervisadas por el autor de cada artículo]

Arte y Costumbres: Los pliegues azules en los vestidos de vinilo de Laura Lima (1990-2010) fue publicado de la página 179 a página190 en Cuadernos del Centro de Estudios de Diseño y Comunicación N76 